\title{
Vertebroplasty with Decompression for Epidural Extending Vertebral Hemangiomas: An Alternative Technique
}

\author{
Orkun KOBAN ${ }^{1}$, Ahmet OGRENCI ${ }^{1}$, Mesut YILMAZ², Sedat DALBAYRAK ${ }^{1}$ \\ ${ }^{1}$ Okan University Medicine Faculty, Department of Neurosurgery, Istanbul, Turkey \\ ${ }^{2}$ Neurospinal Academy, Department of Neurosurgery, Istanbul, Turkey \\ This study has been presented as an oral presentation at the 33. Annual Congress of Turkish Neurosurgical Society between 11 and 14 April \\ 2019 at Antalya, Turkey.
}

Corresponding author: Orkun KOBAN drorkunkoban@gmail.com

\section{ABSTRACT}

AIM: To document the effectiveness of an alternative surgical technique with concurrent vertebroplasty and decompression without instrumentation for patients with vertebral hemangioma presenting with neural compression symptoms.

MATERIAL and METHODS: This study is a technical note and a retrospective clinical evaluation. We analyzed the data of 8 patients operated with our alternative surgical technique for vertebral hemangiomas with epidural extension and neural compression, between 2013 and 2018. The preoperative, postoperative $1^{\text {st }}$ month and postoperative $12^{\text {th }}$-month Visual Analogue Scale (VAS) scores were assessed and compared.

RESULTS: Five of the patients had lumbar and 3 had thoracic hemangiomas. The difference between preoperative and $1^{\text {st }}$ and $12^{\text {th }}-$ month Visual Analogue Scale scores were statistically significant. None of the patients received additional intervention, stabilization, or needed a blood transfusion.

CONCLUSION: This technique is a safe and minimally invasive approach for vertebral hemangiomas with epidural extension allowing decompression of the spinal cord without massive hemorrhage.

KEYWORDS: Decompression, Epidural extension, Vertebroplasty, Vertebral hemangioma

ABBREVIATIONS: CT: Computed tomography, MRI: Magnetic resonance images, MMA: Methyl methacrylate, VAS: Visual analog scale, VH: Vertebral hemangiomas

\section{INTRODUCTION}

$\mathrm{V}$ Tertebral hemangiomas (VHs) are common primary spinal lesions with an estimated incidence of $10-12 \%$ $(2,12,16,21)$. The most common spinal location is in the thoracic vertebrae. Usually, only a single vertebral segment is involved and multiple vertebral involvement is rare $(14,21)$. VHs are usually asymptomatic and only $1 \%$ present with symptoms $(2,16,18)$. If there are symptoms, they could be due to neural compression secondary to enlargement of the lesion or pathological fractures $(15,16,19,34)$. There are very rare reports of spontaneous epidural hematoma formation causing neural compression $(8,34)$.
Treatment options for VHs are surgical or non-surgical. Radiotherapy $(7,22)$, percutaneous vertebroplasty $(5,20,29)$, transarterial embolization and percutaneous ethanol injection $(1,6,19,23,33)$ are non-surgical minimally invasive alternatives when compared to surgical excision $(16,34)$. There are some reports in the literature suggesting that these methods can be used in cases with neural compression, however, it is widely accepted that they fail for adequate spinal canal decompression. Surgical decompression is inevitable and is the primary treatment option if the lesion adjacent to neural tissue $(9,32-34)$.
Orkun KOBAN (1): 0000-0002-4721-0502

Ahmet OGRENCI (1) : 0000-0002-7580-0227
Mesut YILMAZ (1): 0000-0001-8633-7883

Sedat DALBAYRAK (1) : 0000-0001-9538-5190 
Although VHs are benign lesions, their extreme vascular structure increases the risk of massive hemorrhage during surgery $(15-17,19,28)$. VH also reduces the load-carrying capacity of the vertebrae because of a lytic effect on the vertebral corpus, which may result in instability. Additionally, surgical decompression of the lesion may cause iatrogenic instability which may then require stabilization with spinal instrumentation $(4,10,17)$.

In this report, we describe a surgical method for the treatment of $\mathrm{VH}$ with epidural extension and neural compression, by hemilaminectomy with a median approach for excision of the lesion occupying the epidural space, followed by vertebroplasty that also controls hemorrhage, in the same session, without stabilization.

\section{MATERIAL and METHODS}

Eight patients (5 males, 3 females) who underwent surgery with our technique between 2013 and 2018 were included in this study. The mean age at the time of surgery was 32.6 years (range, 13 to 44 years). Preoperative X-rays, spinal computed tomography (CT) scans and magnetic resonance images (MRI) were obtained for each patient. The $\mathrm{VH}$ diagnosis was supported radiologically. The polka-dot sign was observed in CT sections in all patients. Hypointensity on T1weighted images and hyperintensity on T2-weighted images were seen on MRI.

A retrospective assessment of the cases with single level $\mathrm{VH}$ was performed. The inclusion criteria were; the expansion of the mass to the epidural space and failure to control pain with conservative treatment. Patients were initially treated with nonsteroidal anti-inflammatory drugs, bed rest and a corset for about 3 weeks. Patients without neural compression, with accompanying deformities, pathological fractures, multilevel involvement, and patients that needed stabilization for the kyphotic angulation due to depression fracture at the level of the lesion, were excluded from the study.

The preoperative, postoperative $1^{\text {st }}$ and $12^{\text {th }}$-month Visual Analogue Scale (VAS) scores of all patients who underwent surgery with the described technique were evaluated and statistically compared (Table I).

Radiological (CT and MRI) examinations were also performed at the follow-up visits.

\section{Surgical Technique}

The surgery was performed in the prone position under general anesthesia. A longitudinal skin incision of $2 \mathrm{~cm}$ length was made at the level of the vertebra with the $\mathrm{VH}$. The paravertebral muscles were then stripped laterally to reveal only the lamina of the affected vertebra. Bilateral hemilaminectomy was performed for direct visualization of the adjacent dural sac, nerve roots and epidural space for safe application of the vertebroplasty through the affected vertebra. There was no uncontrollable bleeding at this point.

Following hemostasis, one T-handle Jamshidi needle ${ }^{\mathrm{TM}}$ (14 or 16 gauge) was inserted bilaterally via percutaneous transpedicular route under fluoroscopic guidance. After removing the inner piece of the needle, significant bleeding would indicate that the needle was inside the lesion. Under fluoroscopic guidance, the guidewire was inserted into the vertebral body through the $\mathrm{T}$ handle Jamshidi needle ${ }^{\mathrm{TM}}$. The $T$ handle Jamshidi needle ${ }^{\mathrm{TM}}$ was then removed and an application cannula was inserted along the guidewire (Figure $1 \mathrm{~A}, \mathrm{~B})$.

Methyl methacrylate (MMA) bone cement material injections were performed under fluoroscopic guidance to fill the affected vertebral body (Figure 1A, B). To maintain a homogeneous filling of the lesion, each time, the application cannula was pulled a little further towards the posterior edge of the vertebral body.

The amount of retrograde bleeding decreased after the first MMA cement filling because of the decreased blood supply. However, since the vertebroplasty was also aimed at strengthening the vertebral corpus, MMA cement injection was repeated several times to fill the vertebral body. A mean of $9.25 \mathrm{~mL}$ MMA cement was injected. To avoid unnecessary bleeding and prevent retrograde MMA cement leakage, we waited for MMA to solidify before pulling out the cannulae. No MMA cement leakage into the epidural space was observed in any patient.

After the vertebroplasty procedure, the dural sac and nerve root were ruled out, the epidural region was inspected via microscope. The posterior longitudinal ligament was cut and bone occupation in the epidural space was identified. Microsurgical removal of affected region of the vertebral corpus that was causing neural compression was performed through a midline incision. The fragments were excised bilaterally with disc punches and Kerrison rongeurs. Only the parts of the affected corpus intruding into the spinal canal causing neural compression were excised and sent for pathological assessment. The excision was continued until

Table I: The Evaluation of Preoperative and Postoperative VAS Scores

\begin{tabular}{cccc}
\hline & \multicolumn{3}{c}{ Back Pain (VAS) } \\
\hline Patient No. & Preop & $\begin{array}{c}\text { Postoperative } \\
\mathbf{1}^{\text {st }} \text { month }\end{array}$ & $\begin{array}{c}\text { Postoperative } \\
\mathbf{1 2}^{\text {th }} \text { month }\end{array}$ \\
\hline 1 & 8 & 2 & 1 \\
\hline 2 & 9 & 3 & 2 \\
\hline 3 & 7 & 2 & 1 \\
\hline 4 & 8 & 1 & 1 \\
\hline 5 & 7 & 1 & 1 \\
\hline 6 & 7 & 2 & 1 \\
\hline 7 & 8 & 3 & 2 \\
\hline 8 & 9 & 3 & \\
\hline
\end{tabular}

Preop: preoperative, postop: postoperative, VAS: Visual Analogue Scale. 


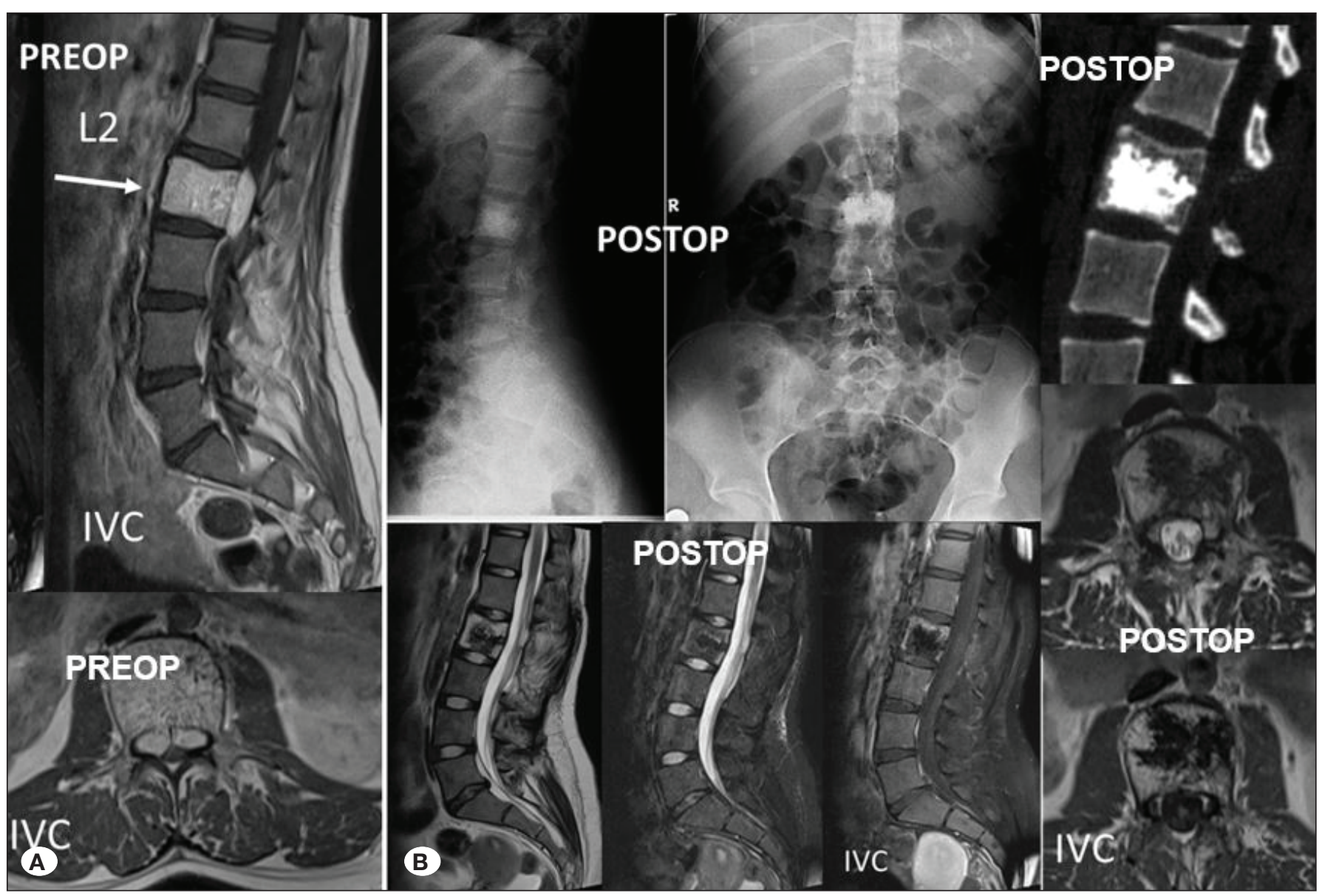

Figure 1: (Case 5) Preoperative and postoperative images of a patient whom was operated with the described technique.

normal epidural level, adjacent structures at below and above was observed and satisfactory decompression of the neural tissues was achieved. Bleeding during this procedure was usually minimal and no massive hemorrhage was seen in any patient. No iatrogenic instability was observed and there was no need for instrumentation in any patient.

This technique provides observation for cement leakage after hemilaminectomy and spinal canal decompression by excision epidural fragments of vertebral hemangioma after vertebroplasty without massive hemorrhage. For aggressive VHs, the technique is minimally invasive method that allows minimal bleeding, a shorter operation time, and smaller skin incisions.

\section{RESULTS}

There were 5 males and 3 females in this study. The average age was 32.6 years (range, 13-44 years) at the time of diagnosis. The mean follow-up time was 41 months.

The main complaint of all patients (100\%) was worsening severe back pain at the level of the affected vertebra (Table I). Motor weakness was a presenting complaint in $87.5 \%$ of the patients and sensory deficits were present in $62.5 \%$.
The average surgical duration was 172.0 minutes (range, 125$210 \mathrm{~min}$ ) and the average blood loss was $318 \mathrm{~mL}$ (range 200$600 \mathrm{~mL}$ ) (Table II). The average injected MMA cement was $9.25 \mathrm{~mL}$ (range $7.5-15 \mathrm{~mL}$ ).

Table II: Detailed Information of Patient Demographic and Clinical Characteristics

\begin{tabular}{cccccc}
\hline Patient & $\begin{array}{c}\text { Age }(\mathbf{y}) / \\
\text { Sex }\end{array}$ & Location & $\begin{array}{c}\text { Surgery } \\
\text { Time } \\
\text { (min) }\end{array}$ & $\begin{array}{c}\text { Blood } \\
\text { loss } \\
\text { (mL) }\end{array}$ & $\begin{array}{c}\text { Follow-up } \\
\text { (months) }\end{array}$ \\
\hline 1 & $44 / \mathrm{M}$ & T8 & 185 & 400 & 38 \\
\hline 2 & $39 / \mathrm{F}$ & T10 & 210 & 600 & 36 \\
\hline 3 & $40 / \mathrm{F}$ & T11 & 145 & 250 & 16 \\
\hline 4 & $32 / \mathrm{M}$ & L2 & 165 & 200 & 50 \\
\hline 5 & $13 / \mathrm{F}$ & L2 & 180 & 300 & 60 \\
\hline 6 & $44 / \mathrm{M}$ & L3 & 125 & 220 & 48 \\
\hline 7 & $40 / \mathrm{M}$ & L3 & 200 & 350 & 28 \\
\hline 8 & $38 / \mathrm{M}$ & L3 & 170 & 220 & 52 \\
\hline
\end{tabular}

F: female, M: male, L: lumbar, T: thoracic, y: years, min: minutes. 
Table III: Preoperative and Postoperative Changes in Pain Scores

\begin{tabular}{|c|c|c|c|}
\hline & Mean & $\begin{array}{l}\text { Standard } \\
\text { Deviation }\end{array}$ & $\mathbf{p}$ \\
\hline Preoperative back pain VAS & 7.88 & 0.83 & \multirow{3}{*}{$<0.0001$} \\
\hline $\begin{array}{l}\text { Postoperative } 1^{\text {st }} \text { month } \\
\text { back pain VAS }\end{array}$ & 2.13 & 0.83 & \\
\hline $\begin{array}{l}\text { Postoperative } 12^{\text {th }} \text { month } \\
\text { back pain VAS }\end{array}$ & 1.25 & 0.46 & \\
\hline
\end{tabular}

*Repeated Measures ANOVA.

Preoperative VAS values between $1^{\text {st }}$ and $12^{\text {th }}$ month repeat measurements were compared. The mean of preoperative back pain VAS was 7.88 and postoperative $1^{\text {st }}$ back pain VAS was 2.13 and postoperative $12^{\text {th }}$ month pain VAS was observed 1.25 The decrease in the trend of back pain VAS were statistically significant.

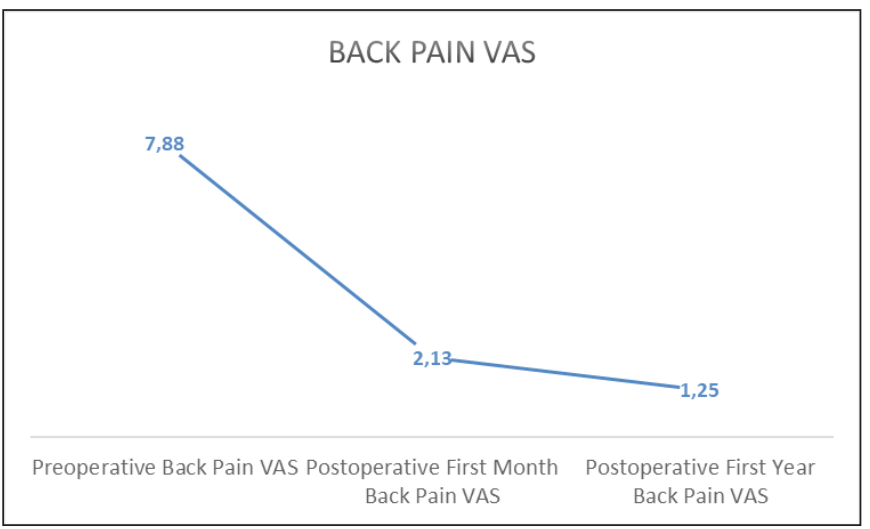

All patients were mobilized in the same day of the procedure. Overall, all patients improved significantly in terms of motor strength, sensory symptoms and pain.

There was a statistically significant improvement observed between preoperative and postoperative $1^{\text {st }}$ and $12^{\text {th }}$-month VAS scores (Table III).

No vertebral depression or height loss with clinical or radiographic signs of recurrence of the lesion was observed during the follow-up period. No additional intervention was required.

\section{DISCUSSION}

On CT scans the typical VH appears as a lesion with small punctate areas, representing sparse thickened hyperdense vertical trabeculae surrounded by hypodense stroma that create the pathognomonic 'polka-dot sign' $(13,31)$. The presence of soft tissue stroma between the osseous trabeculae on a CT scan is considered as a sign of a hypervascular and therefore aggressive lesion $(11,13,24)$. VHs appear as hyperintense lesions on T1- and T2 weighted images on MRI, due to their fat content $(11,13,34)$. However, an aggressive $\mathrm{VH}$ is usually formed of less fat with more hypervascular stroma and therefore may show hypointensity on T1-weighted images and hyperintensity on T2-weighted images $(11,24,31)$. But they appear hyperintensity both in T2 and T1-weighted images with contrast enhancement. Hyperintensity in T1-weighted images with contrast enhancement and 'polka-dot sign' in CT and MRI can help the diagnosis for aggressive VH. All the cases in our series showed the characteristic features of aggressive VHs on CT scans and MRI.

The treatment goals of $\mathrm{VHs}$ may be summarized as local pain control, disruption of the hypervascularity of the lesion, decompression of neuronal structures, strengthening the weakened and affected vertebrae and prevention of local recurrence $(2,16,17,28)$. The treatment options for symptomatic $\mathrm{VHs}$ are; conservative medical therapy, vertebroplasty $(5,10,29)$, transarterial embolization $(1,19,23)$, direct intralesional ethanol injection $(6,18,27,33)$, radiotherapy $(7,22)$ and surgery $(1,4,17,32)$.

The most important determinants of the treatment option are the existence of neural compression and spinal instability. If either is present, surgery should be considered $(4,10,17$, $32,33)$. Neural compression was the priority for our patients. Patients with evident instability at lesion level were excluded from this study. For this reason and based on the literature, only surgical decompression was indicated for our patients $(4,16,17,28,32)$. However, an additional procedure that could prevent bleeding during surgical decompression was performed. It is well-known that the challenging problem in surgical planning for $\mathrm{VH}$ are perioperative and postoperative hemorrhagic complications $(15,17,28,33)$.

Despite advances in technology and surgical techniques, the morbidity and mortality rates associated with surgical management alone are still high $(2,17,26,33)$. Therefore, to reduce these, preoperative transarterial embolization $(1,16,23)$, direct intralesional ethanol injection $(6,33)$, and percutaneous vertebroplasty $(10,20,26)$ are procedures that are reported to be effective. Among these methods percutaneous vertebroplasty, apart from disruption of the highly dynamic vascular structure of VHs, unlike other non-surgical techniques, has the advantage of preventing possible pathological fractures by strengthening the spine. Percutaneous vertebroplasty is a common treatment for VH patients without neural compression $(1,3,20,25)$. However other percutaneous treatments, such as transarterial embolization and direct intralesional ethanol injection, are not sufficient to support the vertebral column, allow spinal canal control, and eliminate the need for decompression.

Due to the discussed advantages, we preferred to perform percutaneous vertebroplasty in the same session as decompression. The criteria that informed our preference were;

1. The ability to perform vertebroplasty and surgical decompression in the same session,

2. To enable early intervention in case of MMA leakage into the epidural area, by performing hemilaminectomy prior to vertebroplasty,

3. To enable rapid decompression in one session, without having to wait for additional treatment protocols for urgent cases experiencing rapid neurological deterioration. 
4. To benefit from the advantages of vertebroplasty such as;

a. Decreasing the amount of surgical bleeding by disruption of $\mathrm{VH}$ hypervascularity.

b. Eliminating the need for additional spinal stabilization by strengthening the weakened vertebrae and preventing possible pathological fractures

C. Providing pain control by creating thermal damage

d. Eliminating the need for radical surgery by excising the affected corpus fragments that intrude into the epidural space

5. To perform all these procedures in a minimally invasive fashion resulting in minimal bleeding, a shorter operation time, and smaller skin incisions.

One of the most common complications of percutaneous vertebroplasty is leakage of MMA material into the spinal canal and neural foramen. This can cause thermal damage or direct neural tissue compression $(3,5,20,25)$. One of the advantages of our technique is, with bilateral hemilaminectomy at the lesion level, the ability to remove immediately if any MMA leaks into the epidural space. During hemilaminectomy, no uncontrollable hemorrhage was observed and control of the epidural space was achieved. Peroperatively, possible MMA leakage into the spinal canal was monitored with the surgical microscope at the hemilaminectomy site. No MMA leakage was experienced in any patient. It can also be concluded that performing hemilaminectomy instead of total laminectomy contributed to reducing perioperative epidural bleeding in addition to its contribution to spinal stability. Another important benefit of starting the operation with a hemilaminectomy is its advantage in cases requiring urgent decompression, such as for patients with rapid neurological deterioration that do not have adequate time for detailed preoperative preparation like embolization $(1,8,9,32)$. Therefore we can conclude that our surgical procedure may be preferable in cases requiring urgent decompression since it does not need any preparation. However, there was no case of rapid neurological progression in our current study.

Another problem in the surgical treatment of diffuse $\mathrm{VH}$ is the presence of preoperative or postoperative (iatrogenic, due to extensive decompression) instability $(1,17,32,34)$. In our series the patients with known obvious instability were excluded from the study. To prevent iatrogenic instability we performed bilateral hemilaminectomy for decompression to preserve axial load-bearing on the posterior vertebral elements (pars, facet joint, lamina). In addition, strengthening the affected vertebral corpus with MMA material not only increased the spinal load-bearing capacity, but it also allowed us to limit our excision to only the affected corpus fragments causing neural compression in the epidural space $(3,5,20,30)$. None of the patients received additional stabilization during surgery or at follow-up.

One of the disadvantages of our technique is that vertebroplasty does not destroy the tumor, and there is a chance of tumor re-growth that may cause spinal cord re-compression $(10,17,20)$. However, there are publications advocating that total removal is not necessary since $\mathrm{VH}$ s are benign lesions, and there is an increased chance of complications during total removal surgery $(17,22,32)$. Recurrent cord compression was not detected in any of the patients during follow-up, and all patients remained asymptomatic with no recurrence, pain, instability or pathological fracture that required additional treatment. Statistically significant pain relief was observed in all patients (Table I).

Performing surgical decompression and vertebroplasty in $\mathrm{VH}$ cases without any additional stabilization is not new. Cotten et al. described a combined technique where each approach was performed in different sessions on consecutive days (10). They first applied transarterial embolization to the affected vertebra followed by percutaneous vertebroplasty the next day. About 3 days following vertebroplasty, laminectomy and excision of the epidural extending fragments of $\mathrm{VH}$ were performed. They did not use any instrumentation during or after these procedures. However, this technique lacks the advantage of simultaneous control of the spinal canal for MMA leakage during vertebroplasty as our technique does (10).

The differences and advantages of our technique can be listed as follows; the ability to perform decompression and vertebroplasty in the same session while taking precautions against MMA leakage by starting with hemilaminectomy. It does not need for additional procedures before the operation also for massive bleeding.

\section{CONCLUSION}

Our surgical technique for VHs with epidural extension provides a safe and minimally invasive method that allows spinal canal decompression and hemorrhage control by performing vertebroplasty in the same session.

\section{REFERENCES}

1. Acosta FL Jr, Dowd CF, Chin C, Tihan T, Ames CP, Weinstein PR: Current treatment strategies and outcomes in the management of symptomatic vertebral hemangiomas. Neurosurgery 58(2):287-295; discussion 287-295, 2006

2. Acosta FL Jr, Sanai N, Chi JH, Dowd CF, Chin C, Tihan T, Chou D, Weinstein PR, Ames CP: Comprehensive management of symptomatic and aggressive vertebral hemangiomas. Neurosurg Clin N Am 19(1):17-29, 2008

3. Amar AP, Larsen DW, Esnaashari N, Albuquerque FC, Lavine SD, Teitelbaum GP: Percutaneous transpedicular polymethylmethacrylate vertebroplasty for the treatment of spinal compression fractures. Neurosurgery 49:1105-1114, 2001

4. Bandiera S, Gasbarrini A, De lure F, Cappuccio M, Picci P, Boriani S: Symptomatic vertebral hemangioma: The treatment of 23 cases and a review of the literature. Chir Organi Mov 87:1-15, 2002

5. Barr JD, Barr MS, Lemley TJ McCann RM: Percutaneous vertebroplasty for pain relief and spinal stabilization. Spine 25:923-928, 2000 
6. Bas T, Aparisi F, Bas JL: Efficacy and safety of ethanol injections in 18 cases of vertebral hemangioma: A mean follow-up of 2 years. Spine 26:1577-1582, 2001

7. Bremnes RM, Hauge HN, Sagsveen R: Radiotherapy in the treatment of symptomatic vertebral hemangiomas: Technical case report. Neurosurgery 39(5):1054-1058, 1996

8. Caruso G, Galarza M, Borghesi I, Pozzati E, Vitale M: Acute presentation of spinal epidural cavernous angiomas: Case report. Neurosurgery 60(3):E575-576; discussion E576, 2007

9. Castel E, Lazennec JY, Chiras J, Enkaoua E, Saillant G: Acute spinal cord compression due to intraspinal bleeding from a vertebral hemangioma: Two case-reports. Eur Spine $J$ 8(3):244-248, 1999

10. Cotten A, Deramond H, Cortet B, Lejeun e JP, Leclerc X, Chastanet $\mathrm{P}$, Clarisse J: Preoperative percutaneous injection of methyl methacrylate and $\mathrm{N}$-butyl cyanoacrylate in vertebral hemangiomas. AJNR Am J Neuroradiol 17(1):137-142, 1996

11. Cross JJ, Antoun NM, Laing RJ, Xuereb J: Imaging of compressive vertebral haemangiomas. Eur Radiol 10(6):9971002, 2000

12. Dagi TF, Schmidek HH: Vascular tumors of the spine. In: Sundaresan N, Schmidek HH, Schiller AL, Rosenthal DI (eds), Tumors of the Spine: Diagnosis and Clinical Management. Philadelphia: W.B. Saunders Co., 1990:181-191

13. Dang L, Liu C, Yang SM, Jiang L, Liu ZJ, Liu XG, Yuan HS, Wei F, Yu M: Aggressive vertebral hemangioma of the thoracic spine without typical radiological appearance. Eur Spine $J$ 21(10):1994-1999, 2012

14. Djindjian M, Nguyen JP, Gaston A, Pavlovitch JM, Poirier J, Awad IA: Multiple vertebral hemangiomas with neurological signs. Case report. J Neurosurg 76:1025-1028, 1992

15. Feuerman T, Dwan PS, Young RF: Vertebrectomy for treatment of vertebral hemangioma without preoperative embolization. Case report. J Neurosurg 65:404-406, 1986

16. Fox MW, Onofrio BM: The natural history and management of symptomatic and asymptomatic vertebral hemangiomas. J Neurosurg 78:36-45, 1993

17. Goldstein CL, Varga PP, Gokaslan ZL, Boriani S, Luzzati A, Rhines L, Fisher CG, Chou D, Williams RP, Dekutoski MB, Quraishi NA, Bettegowda C, Kawahara N, Fehlings MG: Spinal hemangiomas: Results of surgical management for local recurrence and mortality in a multicenter study. Spine (Phila Pa 1976) 40(9):656-664, 2015

18. Goyal M, Mishra NK, Sharma A, Gaikwad SB, Mohanty BK, Sharma S: Alcohol ablation of symptomatic vertebral hemangiomas. AJNR Am J Neuroradiol 20:1091-1096, 1999

19. Graham JJ, Yang WC: Vertebral hemangioma with compression fracture and paraparesis treated with preoperative embolization and vertebral resection. Spine 9:97-101, 1984

20. Guarnieri G, Ambrosanio G, Vassallo P, Pezzullo MG, Galasso R, Lavanga A, Izzo R, Muto M: Vertebroplasty as treatment of aggressive and symptomatic vertebral hemangiomas: Up to 4 years of follow-up. Neuroradiology 51(7):471-476, 2009
21. Hemmy DC: Vertebral hemangiomas. In: Wilkins $\mathrm{RH}$, Rengachary SS, (eds), Neurosurgery. New York: McGraw-Hill, 1996:1827-1829

22. Heyd R, Seegenschmiedt MH, Rades D, Winkler C, Eich HT, Bruns F, Gosheger G, Willich N, Micke O; German Cooperative Group on Radiotherapy for Benign Diseases: Radiotherapy for symptomatic vertebral hemangiomas: Results of a multicenter study and literature review. Int J Radiat Oncol Biol Phys 77(1):217-225, 2010

23. Jayakumar PN, Vasudev MK, Srikanth SG: Symptomatic vertebral haemangioma: Endovascular treatment of 12 patients. Spinal Cord 35:624-628, 1997

24. Laredo JD, Assouline E, Gelbert F, Wybier M, Merland JJ, Tubiana JM: Vertebral hemangiomas: Fat content as a sign of aggressiveness. Radiology 177:467-472, 1990

25. Laredo JD, Hamze B: Complications of percutaneous vertebroplasty and their prevention. Skeletal Radiol 33:493505, 2004

26. Liu XW, Jin P, Wang LJ, Li M, Sun G: Vertebroplasty in the treatment of symptomatic vertebral haemangiomas without neurological deficit. Eur Radiol 23(9):2575-2581, 2013

27. Niemeyer T, McClellan J, Webb J, Jaspan T, Ramli N: Brown-Sequard syndrome after management of vertebral hemangioma with intralesional alcohol. A case report. Spine 24:1845-1847, 1999

28. Pastushyn Al, Slin'ko El, Mirzoyeva GM: Vertebral hemangiomas: Diagnosis, management, natural history and clinicopathological correlates in 86 patients. Surg Neurol 50:535-547, 1998

29. Peh WC, Gilula LA: Percutaneous vertebroplasty: Indications, contraindications, and technique. Br J Radiol 76:69-75, 2003

30. San Millan Ruiz D, Burkhardt K, Jean B, Muster M, Martin JB, Bouvier J, Fasel JH, Rufenacht DA, Kurt AM: Pathology findings with acrylic implants. Bone 25:85S-90S, 1999

31. Schrock WB, Wetzel RJ, Tanner SC, Khan MA: Aggressive hemangioma of the thoracic spine. J Radiol Case Rep 5(10):713, 2011

32. Shah KC, Chacko AG: Extensive vertebral haemangioma with cord compression in two patients: Review of the literature. $\mathrm{Br}$ J Neurosurg 18:250-252, 2004

33. Singh P, Mishra NK, Dash HH, Thyalling RK, Sharma BS, Sarkar C, Chandra PS: Treatment of vertebral hemangiomas with absolute alcohol (ethanol) embolization, cord decompression, and single level instrumentation: A pilot study. Neurosurgery 68(1):78-84; discussion 84, 2011

34. Vinay S, Khan SK, Braybrooke JR: Lumbar vertebral haemangioma causing pathological fracture, epidural haemorrhage, and cord compression: A case report and review of literature. J Spinal Cord Med 34:335-339, 2011 